\section{Exercise prescription: bridging the gap to clinical practice}

\author{
Philip Glasgow
}

Exercise works, exercise is medicine-this is something most readers will attest to. Exercise is the first line of intervention for many clinical presentations and has been repeatedly shown to outstrip pharmacological and surgical approaches to the management of a wide range of medical, musculoskeletal and psychological conditions. Whether we are physiotherapists, physicians, sports scientists or other sport and exercise medicine practitioners, we regularly prescribe exercise programmes to patients with a host of different symptoms.

\section{GETTING THE RIGHT PRESCRIPTION}

While not a panacea, exercise is an intervention that has a role to play in every aspect of sport and exercise medicine. In a sense our first question when considering treatment options should be, 'What type of exercise should I prescribe?' rather than 'Should I prescribe exercise?' But what guides our decision-making in determining the nature, type and volume of exercise for our patients? As with anything we prescribe, we should seek to ensure that we prescribe for the greatest therapeutic benefit and tailor it to the needs of each individual. What is the best dose?

This issue of BJSM provides us with some great material encouraging us to consider some of these questions as well as providing some challenging answers that help bridge the gap from research to clinical practice.

\section{ASSISTING OPTIMAL LOADING}

It is incongruous that we should promote the idea of adding permanent external support to an injured area without

Correspondence to Professor Philip Glasgow, Sports Institute Northern Ireland, University of Ulster, Newtownabbey, Co. Antrim BT37 OQB, UK; philglasgow@sini.co.uk attempting to increase the strength of the local system. Yet this is what McKeon and colleagues suggest is often done in the management of foot injuries (see page 290). They challenge us to consider the muscular support system of the foot, the so-called, foot core, to focus on improving both the static and dynamic properties of these muscles. Orthotics may then be viewed as a temporary-assistive device that can be used to facilitate effective strengthening of the foot core rather than a permanent treatment. It is reasonable to conclude that specific exercises to strengthen local tissues are preferable to the use of passive external support in other parts of the body. This concept can be extrapolated to the use of supports, braces and assistive devices to facilitate optimal loading rather than a way of minimising loading.

\section{NOT JUST 'THE WHAT' BUT 'THE HOW'}

The message is clear-exercise works, whether it is specific or general. Beaudreuill and colleagues describe how a specific exercise programme focusing on dynamic humeral centring can positively influence pain and range of motion in patients with subacromial impingement (see page 343 ). The authors highlight that the effectiveness of the exercise intervention lies in the quality of the movement that is performed. We are reminded that in determining the most effective exercise prescription, it is not enough to simply describe what exercises to do but to also describe how they should be performed. This is a concept highlighted in the editorial considering the nature of optimal loading (see page 278); the authors remind us that optimal loading influences multiple biological systems including the nervous system and that optimal movement will also be coordinated movement.

\section{CLINICALLY RATHER THAN} RADIOLOGICALLY DIRECTED

The shoulder is a complex region for which a wide range of therapeutic interventions have been described. In an erudite editorial (see page 280) Jeremy Lewis challenges us to reconsider perceptions about the relevance of subacromial decompression surgery highlighting that appropriately constructed exercises have at least comparable results to surgery with lower associated costs. Similarly, Hallgren et $a l^{1}$ demonstrate that completion of a specific exercise programme for patients with subacromial pain significantly improves pain and functional performance and reduces the proportion of patients requiring surgery. They further highlight that the outcome of the exercise intervention was not related to radiographic findings but to key functional and clinical measures; the old adage, 'treat the patient not the scan' springs to mind.

As with any intervention, specific exercises may be more effective for particular subgroups. One such group is the adolescent athlete-the theme for the ACPSEM (Physios in Sport) biennial conference in 2015. The programme brings together international and national experts to consider effective management and exercise prescription in this unique population. The conference will be held on 9-10 October 2015 in Brighton, England. For more details please visit http://www. physiosinsport.org.

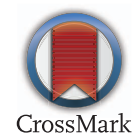

To cite Glasgow P. Br J Sports Med 2015;49:277.

Accepted 7 December 2014

Br J Sports Med 2015;49:277

doi:10.1136/bjsports-2014-094485

\section{REFERENCES}

1 Björnsson Hallgren HC, Holmgren T, Birgitta Öberg B, et al. A specific exercise strategy reduced the need for surgery in subacromial pain patients. $\mathrm{Br} / \mathrm{Sports} \mathrm{Med}$ 2014;48:1431-6. 